\title{
INSTRUMENTAL ODOUR MONITORING: ACTIONS FOR A NEW EUROPEAN STANDARD
}

\author{
Anne-Claude Romain ${ }^{1}$, Laura Capelli ${ }^{2}$, Jean-Michel Guillot ${ }^{3}$ \\ ${ }^{1}$ University of Liege, Arlon Campus Environnement, Av. de longwy 185, B-6700 Arlon, Belgium; \\ ${ }^{2}$ Politecnico di Milano, Dpt of Chemistry, Materials and Chemical Engineering "Giulio Natta", \\ 20133 Milano, Italy; ${ }^{3}$ Ecole des Mines d'Alès, LGEI-Odours and VOCs, 6 av. de Clavières, F-30319 \\ Alès cedex, France.
}

\begin{abstract}
Odour concentration is measured sensorially, thus needing a human panel, whereas the measurement of odorous compounds is typically based on physical and chemical analysis. Some systems such as electronic noses try to correlate both approaches in order to measure odour instrumentally, which would allow monitoring odour continuously. In the domain of instrumental odour monitoring, e-noses are the main candidates, although a wide range of devices based on different sensing technologies and data processing methods can be used for this purpose. Such devices are already applied in different situations, especially for monitoring of odours in ambient air. However, up to now, there is still neither standardization nor regulatory reference for this technology. In 2015, a European working group (WG41), in the frame of technical comittee CEN/TC264 Air Quality, was established aiming to develop a standard related to instrumental odour monitoring. This paper presents the scope and the general outline of this forthcoming standard.
\end{abstract}

Index Terms - European standard, sensors, electronic nose, continuous measurement, odour

\section{INTRODUCTION}

Since the introduction of the concept of artificial olfaction in 1982 by Persaud and Dodd [1], the scientific interest in the development of an electronic instrument mimicking the sense of olfaction has rapidly increased. In 1991, the first conference on the electronic nose, a term proposed by Julian Gardner and adopted by the scientific community, is organised in Reykjavik, Iceland and sponsored by NATO Science committee [2]. The first commercial instruments arrived in 1992 (Néotronic, OdourLMapper, AlphaMos,...). However, after more than 20 years of history, as far as the environmental sector is concerned, despite some examples of successful applications [3], the use of these devices in real-life applications is still limited [4]. Besides some technical limitations (e.g., cross-sensitivity to humidity, drift,...), one obstacle to their large-scale application is the lack of technical and conceptual validation as well as the absence of specific standardization of the method. Electronic noses for environmental monitoring are usually complex instruments, and their use entails a large number of degrees of freedom, as well as a lot of problematic aspects, concerning mainly the difficulty to obtain a metric characterising an odour, which is a sensation, with an electronic device [5].

A first standardization attempt, fixing how to apply electronic noses in environmental monitoring, was undertaken by the NTA-905, which is a technical agreement document released in December 2012 by the Netherlands Standardization Institute.

Stimulated by this national regulation, a new European working group was established within CEN TC 264 Air Quality to draft a standard related on instrumental odour monitoring systems. The working group CEN/TC264/WG41 started in 2015 with the objective to define a new European standard on this topic. The WG41 is composed by experts nominated by national standard organisations from European countries that are CEN members, including Belgium, France, Germany, Italy, Netherlands, Spain, UK. The working group is facilitated by a convenor with the help of a secretariat provided by NEN, the standardisation organisation of the Netherlands.

\section{SCOPE OF THE STANDARD}

This European Standard specifies systems requirements for the monitoring of odour in ambient air, in indoor air and in emissions to ambient air (odorous gas sources as well as odour abatement equipment).

The crucial function of these systems is to generate metrics that are relevant indicators for the presence and attributes of odour as would be perceived by human observers. A benefit of instrumental odour monitoring systems is that they can be used for continuous measurement.

Odour monitoring systems are typically limited in their ability to mimic human olfaction and their very specific sensitivity to a large number of odorants and also non odorous compounds. Human olfaction involves olfactory receptor cells, from which the signals are aggregated in the brain to one odour perception. 
Table 1: currently working topics of the 4 task groups

\begin{tabular}{|l|l|}
\hline Task Group & Topic \\
\hline TG1 & Minimum requirements for instrumental odour monitoring systems \\
\hline TG2 & Establishing and validating the relationship between odour metric and odour \\
\hline TG3 & Terms and definitions \\
\hline TG4 & Descriptions and review of scope relevant technologies \\
\hline
\end{tabular}

Odour monitoring systems are typically less evolved and therefore currently only give indicative results.

Current non-specific sensors are sensitive to both odour relevant molecules and also to odour irrelevant molecules. They are subject to being affected by interferences such as humidity and temperature. This can lead to both false positive and false negative signals as far as odour relevance is concerned.

The quality of the electrical signal from the sensors, the mathematical treatment and the validation of correlation of the odour metric with human odour perception are therefore key topics in this European Standard.

To complete this scope, the standard is also applicable to the method of:

- correlating sensor signal based metrics to the presence and attributes of odour,

- validating the sensor signal based metrics to the presence and attributes of odour.

Odour concentration, expressed in $\mathrm{ou}_{\mathrm{E}} / \mathrm{m}^{3}$, is measured according to EN 13725. The metric produced by an instrumental odour monitoring method can only be correlated to the odour concentration benchmark measured according to EN13725. Moreover, because pleasantness or unpleasantness is linked to psychology, hedonic tone cannot be nowadays monitored by an instrument.

For these two reasons, direct assessment of odour annoyance is also excluded.

Finally, because developments and technical improvements must go on, the technical design of the sensors for odour detection or the specific odour measurement system will not be fixed in this standard.

These aspects, describing applicability domains and exclusions, delimit the scope of the standard.

As all measurement method, sampling, uncertainty of the measurement, data collection must be also discussed in the standard.

\section{WORKING GROUP AND SPECIFIC TASK GROUPS}

The WG41 is composed of experts from European countries (Belgium, France, Germany, Italy, Netherlands, Spain, UK). Specific task groups have been formed in order for the development of specific topics of the standard in smaller expert groups. The task groups are mentioned in Table 1. These task groups are typically in charge to draft proposals on key points of the future standard. Obviously, all decisions are taken by the plenary WG41.

Up to now; five meetings were organized (November 2015, Antwerp; February 2016, Nîmes; June 2016 Delft; October 2016 Bilbao; February 2017 Barcelona), during which the future standard was outlined and the work of the task groups has been defined and initiated.

In more detail, the first important point of the discussion was the definition of the title of the standard. "Instrumental odour monitoring" is the result of the intentions to consider any generic "instrument" (without specifying the type of instrument nor the sensing technology) capable of giving an information about "odour" as a whole, thereby referring to "odour" as an "organoleptic attribute perceptible by the olfactory organ on sniffing certain volatile substances", and not only to single odorants.

By now, TG3 has almost finished its work of establishing terms and definitions relevant to the scope of the standard.

Moreover, a significant task was undertaken by the TG4 coordinator who has prepared a detailed document reviewing and describing the main sensor types used in electronic nose systems, thereby also highlighting their pros and cons specifically for environmental applications.

TG1 has started work in the direction of defining requirements for instrumental odour monitoring systems. The reason for the existence of this TG is that it is of crucial importance to define specific objectives and limitations, thus establishing precise procedures aiming to verify the instrument suitability for any specific application and its use.

It was agreed by the WG41 members that, given the wide range of different instruments for odour monitoring available on the market, often based on different gas sensing systems and functioning principles, standardization in this field cannot concern the instrument hardware, instead, it should define the instrument performance requirements specifics for odour measurements. 
The definition of performance requirements should involve both the identification of the aspects for which performance needs to be guaranteed as well as the procedures to verify those performances.

Such requirements should be intended as applicationspecific, and therefore be defined for each of the applications included in this standard, which are odour monitoring in ambient air, in indoor air and in emissions to ambient air.

Moreover, to be effective for odour measurement, the instrument must be able to:

- detect the presence or absence of odour above a given threshold (i.e. instrument detection limit)

- identify and classify the present odours at different concentrations

- $\quad$ quantify the odour (odour magnitude)

- give stable responses with varying atmospheric conditions $(\mathrm{T}, \mathrm{RH})$.

It was also defined that features and target odour concentration ranges for the definition of performance requirements have to be considered top be applicationspecific.

Moreover, since the scope of this standard is the instrumental monitoring of odour - considered as a whole and not only of single odorants, it is important to express the target concentrations in terms of sensorial magnitude, i.e the odour concentration, more than the chemical concentration. For this reason, in the following sections the target concentrations are expressed in terms of $\mathrm{ou}_{\mathrm{E}} / \mathrm{m}^{3}$. When referring to single odorants, its analytical concentration is univocally determinable by dividing the odour concentration by the Odour Threshold (OT) concentration of the compound.

Thus, features and target odour concentrations were proposed for the following fields of odour monitoring:

In ambient air:

- Detection of odour (presence or absence): 0.1-10 ouE $/ \mathrm{m}^{3}$

- Identification/classification of odours: 1-100 ou$/ \mathrm{m}^{3}$

- Quantification of odour magnitude: 1-200 ouE $/ \mathrm{m}^{3}$

In emissions:

- Classification/identification: not necessarily

- Quantification of odour magnitude: 100-100000 ouE $/ \mathrm{m}^{3}$

In indoor air:

- Detection of odour (presence or absence): 0.1-10 ou $/ \mathrm{m}^{3}$

-Identification/classification of present odours:1-100 ou $/ \mathrm{m}^{3}$

- Quantification of odour magnitude: 1-200 ouE $/ \mathrm{m}^{3}$
The work of TG1 is currently going on with the aim of identifying the target odorous reference gases" to be tested and of defining the testing procedures.

What was agreed up to now is that the target "odours" should be standardized and reproducible in any laboratory, which makes that they cannot be 'real-life odours' but rather synthetic mixtures of standard odorous compounds

The task of TG2 is probably the most difficult one, since the possibility to relate the metric which is the output of an instrument with a sensation is a tricky issue, and it represents the major challenge of the WG41 in the development of the future standard on instrumental odour monitoring.

\section{CONCLUSIONS}

This new European committee on instrumental odour monitoring has a difficult task: standardize instruments aimed at mimicking sensorial odour measurement! After 5 intense meetings organized in a short period of only about 1 year, the outline of the various tasks is already delimited. The experts are aware that the fundamental work is not yet fully started. They will be confronted with tricky issues but this standard will be helpful in introducing instrumental monitoring systems in air quality management. Moreover, this future standard will set the requirements for, at least, a credible use of devices for the monitoring of odors in ambient, emissions and indoor air.

\section{AKNOWLEDGEMENTS}

We thank the members of the working group 41 for their contribution, especially Pierluigi Barbieri, Franz-Bernd Frechen, Andrea Rossi, Thomas Hubert and the convenor of this committee, Ton Van Harreveld

\section{REFERENCES}

1 K.C. Persaud, and G. Dodd, "Analysis of discrimination mechanisms in the mammalian olfactory system using a model nose" Nature 299, pp. 352-355, 1982.

2 J.W. Gardner, and P.N. Bartlett, "Sensors and sensory systems for an electronic nose", Kluwer Academic, London, 1991.

3. W. Bourgeois, A-C Romain, J. Nicolas and R.M. Stuetz, "The use of sensor arrays for environmental monitoring: interests and limitations", J. Environ. Monit. Vol 5; iss.6, pp. 852-860, 2003.

4 L. Capelli, S. Sironi, and R. Del Rosso, "Electronic Noses for Environmental Monitoring Applications", Sensors 14, pp. 19979-20007, 2014.

5. P. Boeker, "On 'Electronic Nose' methodology" Sens Actuat B-Chem 204, pp. 2-17, 2014. 